\title{
INVESTIMENTOS EM CAPITAL HUMANO E DESEMPENHO ORGANIZACIONAL: ANÁLISE EM COMPANHIAS BRASILEIRAS
}

\author{
INVESTING IN HUMAN CAPITAL AND ORGANIZATIONAL PERFORMANCE: \\ ANALYSIS IN BRAZILIAN COMPANIES
}

\author{
Eduardo Vinicius Bassi Murro \\ eduardo.murro@gmail.com \\ Universidade Federal do Paraná \\ Romualdo Douglas Colauto \\ rdcolauto@yahoo.com.br \\ Universidade Federal do Paraná
}

\author{
Flávio Ribeiro \\ flayribeiro@hotmail.com \\ Universidade Federal do Paraná \\ Ramon Kael Benassi Bachmann \\ ramon_bach@yahoo.com.br \\ Universidade Federal do Paraná
}

Joyce Menezes da Finseca Tonin
joycemftonin@ gmail.com
Universidade Federal do Paraná

\section{RESUMO}

Este artigo investigou a relação entre os indicadores sociais internos e a rentabilidade das companhias que divulgam o Balanço Social. A amostra é compreendida por vinte empresas brasileiras de capital aberto que divulgaram as informações relacionadas ao Balanço Social no período de 2006 a 2010. Com a utilização do modelo de dados em painel, os resultados encontrados, embora apresentem implicações conflitantes, demonstram que investimentos em capital humano impactam o desempenho organizacional, considerando os indicadores de rentabilidade do ativo e do patrimônio líquido. Quando os investimentos estão alinhados com programas de saúde, educação e participação nos resultados o desempenho da empresa tende a responder positivamente. Contudo, quando a empresa aplicar parte de seu capital em programas de segurança e previdência privada o desempenho tende a ser minimizado. Portanto, a pesquisa em âmbito contábil, além da contribuição teórica, contribui para uma possível criação de vantagem competitiva às organizações, considerando que determinados investimentos no corpo funcional podem estar diretamente relacionados ao desempenho das empresas. Além disso, estudos sobre avaliação da gestão de capital humano com o uso de indicadores sociais ajudam a compreender a influência da divulgação de informações sobre pessoas por meio de indicadores sociais no desempenho financeiro das companhias que se comprometem com aspectos sociais.

PALAVRAS-CHAVE: Capital Humano; Indicadores Sociais Internos; Desempenho Organizacional.

\section{ABSTRACT}

This paper investigated the relationship between internal social indicators and profitability of companies that disclose the Social. The sample is comprised of 20 publicly traded Brazilian 
companies that disclose information related to Social in the period from 2006 to 2010. Using the panel data model, the results demonstrate that, although have conflicting implications, investments in human capital affect the organizational performance. When investments are aligned with health programs, education and profit performance of the company tends to respond positively. However, when the company was part apply its capital in security programs and pension plan performance tends to be minimized. Therefore, in accounting framework, the research offers a theoretical contribution, as well as contributes to a possible creation of competitive advantage for organizations, considering that certain investments in the human capital can be directly related to company performance. Furthermore, studies on evaluation of human capital management with the use of social indicators help to understand the influence of disclosure of information about people through social indicators in the financial performance of companies that are committed to social aspects.

KEYWORDS: Human Capital; Internal Social Indicators; Organizational Performance.

Artigo recebido em: 17/12/2013; Aceito em: 13/11/2014

\section{INTRODUÇÃO}

A competição econômica desencadeia a necessidade de identificar variáveis que permitam às organizações obterem vantagens competitivas. Kaplan e Norton (1996) descrevem que essas variáveis residem na capacidade de desenvolver relações sustentáveis com clientes e inovar na criação de bens e serviços com qualidade que antecipem as expectativas dos clientes. Assim, a permanência das organizações no mercado requer a busca por maneiras eficientes de gerenciar seus ativos intangíveis, em especial, os relacionados ao capital humano. Embora o capital físico e financeiro, na sociedade industrial, representasse fatores preponderantes para o sucesso organizacional, o capital humano os superam ajudando as corporações a obterem melhor desempenho econômico-financeiro (CRAWFORD, 1994).

Yang (2010) descreve que o capital humano tornou-se um fator preponderante na obtenção de vantagem competitiva nas últimas décadas. Associado ao processo de transformação da economia mundial para uma sociedade baseada em conhecimento, o conhecimento humano caracterizou-se como um recurso econômico que impôs novos paradigmas na forma de valorizar o ser humano e valorizar a organização (ANTUNES, 2000). Adam Smith já no século XVII ressaltava a importância do capital humano como um ponto central na transformação econômica. Na sua obra Riqueza das Nações, de 1776, o autor introduziu a noção do ser humano como capital para as organizações. No entanto, apenas na década de 60, com trabalhos de Theodore W. Schultz, em 1961, e Gary Becker, em 1964, é que se começou a atribuir valor ao fator humano pela sua capacidade de gerar benefícios (CUNHA, 2007). Desde então, pesquisas (ANTUNES, 2000; TEECE, 2000; COLAUTO; BEUREN, 2003; KATOU, 2008; MIZUMOTO et al., 2010) vem sendo realizadas com o propósito de analisar esse recurso econômico e seu reflexo na organização.

Sveiby (1997) e Stewart (1998) veem a gestão de conhecimento humano a partir do pressuposto de que o valor empresarial deixou de ser alocado a bens tangíveis, como máquinas e construções, passando a ser associado essencialmente aos bens intangíveis. Em virtude disso, persistem críticas em relação à divergência entre o valor econômico das empresas e seu valor contábil líquido. Tal diferença é atribuída à presença de ativos intangíveis, principalmente ao item de capital relacionado a pessoas (SVEYBY, 1997; ANTUNES; MARTINS, 2007).

R. Cont. Ufba, Salvador-Ba, v. 8, n. 3, p. 38 - 51, set-dez 2014 
O fato de o valor empresarial estar associado ao capital humano da empresa apoia-se na ideia de que investimentos em pessoas afetam positivamente o desempenho econômico e financeiro das empresas (RASULA; VUKSIC; STEMBERGER, 2012). Nesse sentido, a necessidade de gerenciamento do conhecimento humano é essencial para criar e manter o diferencial competitivo na era da informação (COLAUTO; BEUREN, 2003). Assim, admitir a importância do conhecimento humano como fonte de criação de valor para a empresa, realça a suposição que investimentos realizados no capital humano promovem resultados positivos em elementos das demonstrações contábeis (ANTUNES; MARTINS, 2007), refletindo dessa forma, no desempenho organizacional.

Nesse contexto, o Balanço Social pode ser visto como instrumento capaz de captar os dados referentes a investimentos relacionados ao capital humano da empresa (KROETZ, 2000). Diante disso, o presente estudo contempla a seguinte questão de pesquisa: Qual a relação entre os indicadores sociais internos e a rentabilidade das companhias que divulgam o Balanço Social? Assim, o objetivo desse estudo consiste em verificar a relação entre os indicadores sociais internos e a rentabilidade das companhias que divulgam o Balanço Social.

A realização desta pesquisa justifica-se, inicialmente, pela sua contribuição teórica, dada a escassez de estudos envolvendo essas variáveis em âmbito nacional. Não se identificaram estudos no Brasil que utilizaram como métrica os indicadores sociais internos disponibilizados no Balanço Social para mensurar os investimentos no corpo funcional das entidades, e as possíveis relações com o desempenho das empresas, a partir dos indicadores de rentabilidade do ativo e do patrimônio líquido.

Justifica-se também pela relevância do tema para as organizações, uma vez que contribui para uma possível criação de vantagem competitiva considerando que determinados investimentos no corpo funcional podem estar diretamente relacionados ao desempenho das empresas. Ressalta-se que, em âmbito contábil, estudos sobre avaliação da gestão de capital humano com o uso de indicadores sociais ajudam a compreender a influência da divulgação de informações sobre pessoas por meio de indicadores sociais no desempenho financeiro das companhias que se comprometem com aspectos sociais.

\section{A TEORIA DO CAPITAL HUMANO}

A expressão capital humano associa-se a um grupo de competências produtivas dos seres humanos constituída pelo conhecimento, habilidades e atitudes que produzem resultado a uma economia (BECKER, 1962, BAPTISTE, 2001). Nesse sentido, a teoria do capital humano é respaldada no conceito de que a aquisição de conhecimento e habilidades agrega valor ao capital humano das pessoas, melhorando sua produtividade e seu rendimento (CUNHA, 2007).

Embora o capital humano seja um fator essencial para o desempenho das organizações, Baptiste (2001) descreve que após o reconhecimento desse conceito por Adam Smith em 1776, a teoria do capital humano ficou inerte por aproximadamente dois séculos. Essa inércia foi atrelada principalmente pela divergência de opinião entre os teóricos em relação ao homem, trabalho, lucro e capital. E, desta divergência surgiram três correntes. A primeira liderada por John Stuart Mill e Alfred Marshall defendia que a ideia de associação do homem com o capital era ofensiva, pois o homem representava a único propósito da existência de capital e da riqueza. A segunda corrente, conduzida por Adam Smith e Irving Fisher, via a relação do homem com o capital contrário a sua concepção de liberdade e dignidade, logo seus limites de liberdade eram ampliados à medida que as pessoas investiam em si mesmas. A terceira corrente, defendida por Karl Marx, aceitava a visão da venda do poder de trabalho pelo trabalhador em vez da venda 
de si mesmo. No entanto, divergia quando defendia que a criação do capital humano se dava com o uso do poder de trabalho no processo produtivo (CUNHA, 2007).

A adoção da visão Keinisiana para definição de investimento foi outro fator responsável pelo atraso no desenvolvimento da teoria do capital humano. A relação excludente entre consumo e investimento atribuía à educação a qualidade de gasto, portanto, sem qualquer elemento de investimento. Por fim, o terceiro fator refere-se às características rudimentares da economia antes da Segunda Guerra Mundial, em que a falta de trabalhadores especializados impediu o desenvolvimento do capital humano.

Em meados da década de 60, a expressão capital humano apareceu pela primeira vez na literatura econômica (CRAWFORD, 1994), no artigo publicado na American Economic Review, intitulado Investimento em Capital de Humano, de Theodore W. Schultz. Nesse artigo, o autor defende a educação como uma forma de investimento do ser humano, apoiando a ideia de que o conhecimento adquirido é uma forma de capital. Logo após o trabalho de Schultz (1961), Gary Becker, em 1964, publicou seu livro intitulado Human Capital, no qual expandiu o conceito por meio do desenvolvimento de uma teoria de investimentos em capital humano com ênfase em implicações empíricas. Com o propósito de preencher lacunas para a explicação dos fenômenos relacionados ao capital humano, Becker (1964) investigou a capacidade de certas atividades afetarem o futuro bem-estar e a renda real das pessoas (CUNHA, 2007).

Embora o conceito de capital humano fosse originalmente associado ao estudo do valor econômico da educação (SCHULTZ, 1961), ele compreende a noção de que as pessoas apresentam um agregado de capacidades, competências e experiência com valor econômico para as organizações (HUSELID; BECKER, 1997).

Pesquisas como de Snell e Dean, (1992) têm transportado esse conceito para o estudo dos recursos humanos, respaldados no princípio que dada à importância do capital humano para a organização, quanto maior for o investimento nesse ativo, maior será o retorno para a empresa, e consequentemente, melhor será seu desempenho. Nessa linha, estudos (ARTUR, 1994; KATOU 2008; GRAÇA, 2011) tem sido realizados com o enfoque da relação entre investimentos em capital humano e desempenho organizacional.

Artur (1994) entrevistou os gerentes do setor de recursos humanos de 30 usinas de aço dos EUA, no período de novembro de 1988 a março de 1989, e relatou como resultados a relação positiva entre os investimentos em capital humano e o desempenho das usinas. Katou (2008) investigou o impacto do gerenciamento do capital humano no desempenho de empresas gregas, com base nos dados coletados por meio de 178 questionários aplicados ao setor de manufatura Greco, encontrando indícios da relação positiva entre as práticas de gestão de capital humano e o desempenho organizacional.

Graça (2011) analisou o impacto que os investimentos no capital humano podem ter no fortalecimento da posição competitiva das empresas e sua viabilidade futura. Com base nos relatórios e Balanços Sociais do ano de 2008 de 33 unidades hospitalares de Portugal, a autora buscou verificar a análise entre os indicadores sociais e cinco indicadores econômicofinanceiros: Valor Agregado Bruto (VAB), Volume de Negócios (VN), Resultados Operacionais (RO), Earnings Before Interest, Taxes, Depreciation and Amortization (EBITDA) e Retorno do Investimento em Capital Humano (ROICH). Os resultados mostraram que os investimentos em capital humano podem influenciar tanto positiva como negativamente o desempenho da empresa. A partir de inspirações metodológicas dessas pesquisas relatadas, o presente estudo se propõe a analisar a relação entre de investimentos em capital humano e desempenho empresarial, utilizando os indicadores sociais internos do balanço social como proxies para investimentos sociais. 


\section{METODOLOGIA DA PESQUISA}

O estudo se caracteriza como descritivo, com abordagem quantitativa do problema, e busca mostrar a relação entre os indicadores sociais internos e o desempenho financeiro das empresas de capital aberto. No quadro 1, apresenta-se a amostra da pesquisa compreendida por vinte empresas brasileiras de capital aberto que divulgaram as informações relacionadas ao Balanço Social no período de 2006 a 2010. As informações referentes aos indicadores de rentabilidade foram extraídas da base de dados da Economática ${ }^{\circledR}$ e aos indicadores sociais internos, os dados foram coletados dos Balanços Sociais divulgados.

Quadro 1 - Amostra da pesquisa

\begin{tabular}{|lc|}
\hline \multicolumn{1}{|c|}{ Empresas } & Setores \\
AES Sul Distrib. Gaúcha de Energia S.A. & Energia Elétrica \\
AES Tietê S.A. & Energia Elétrica \\
Afluente Geração e Transmissão de Energ. Eletrica S.A. & Energia Elétrica \\
Ampla Energia e Serviços S.A. & Energia Elétrica \\
Celesc - Cent. Elétricas de Santa Catarina S.A. & Energia Elétrica \\
Celpe - Cia Energética de Pernambuco & Energia Elétrica \\
Coelba - Cia de Eletricidade do Estado da Bahia & Energia Elétrica \\
Coelce - Cia Energética do Ceará & Energia Elétrica \\
Copasa - Cia de Saneamento de Minas Gerais & Outros \\
Copel - Cia Paranaense de Energia Elétrica & Energia Elétrica \\
Cosern - Cia Energética do Rio Grande do Norte & Energia Elétrica \\
CPFL Energia S.A. & Energia Elétrica \\
Embraer - Emp. Brasileira de Aeronáutica S.A. & Outros \\
Eletropaulo Metrop. Eletricidade de São Paulo & Energia Elétrica \\
Localiza Rent a Car S.A. & Outros \\
Neoenergia S.A. & Energia Elétrica \\
Petrobras - Petróleo Brasileiro S.A. & Petróleo e Gás \\
SLC Agrícola S.A. & Agro e Pesca \\
Usiminas - Usinas Siderúrgicas de Minas Gerais S.A. & Sider. \& Metalur. \\
Vale do Rio Doce & Mineração \\
\hline
\end{tabular}

Fonte: Dados da pesquisa.

Para mensurar o desempenho financeiro das empresas foram utilizadas separadamente, como variáveis dependentes, o ROA - Retornon Assets (Retorno sobre ativos) e ROE - Retornon Equity (Retorno sobre Patrimônio Líquido). Assaf Neto (2003) descreve que o indicador do Retorno sobre o Ativo revela o retorno produzido pelo total das aplicações realizadas por uma empresa em seus ativos. Uma melhor relação deste índice dará maior remuneração dos seus investimentos aplicados no Ativo (Bens e Direitos). No cálculo deste indicador é utilizado o Lucro Líquido. Para se calcular o ROA, utiliza-se a fórmula demonstrada a seguir:

$$
R O A=\frac{L L}{A T I V O_{\mathrm{t}-1}}
$$

Em que,

ROA - Retorno sobre o Ativo

LL - Lucro Líquido

ATIVOt-1- Total de Ativos

R. Cont. Ufba, Salvador-Ba, v. 8, n. 3, p. 38 - 51, set-dez 2014 
Segundo Grapelli (1998), o índice do Retorno sobre o Patrimônio Líquido (ROE) mede a taxa de retorno para os acionistas. Os analistas de mercado de capitais, tanto quanto os acionistas, estão especialmente interessados neste índice. Em geral, quanto maior o retorno, mais atrativa é a ação. Dessa forma, representa o retorno obtido sobre o valor investido pelos sócios no empreendimento, ou seja, quanto os acionistas auferem de Lucro para cada unidade monetária de recursos próprios (PL). O papel deste índice é mostrar qual a taxa de rendimento do capital próprio, inclusive com o objetivo de comparar com a taxa de retorno de outros investimentos no mercado.

O Retorno sobre o Patrimônio Líquido está relacionado a três tópicos importantes para acelerar ou desacelerar uma empresa: lucratividade, administração de ativos e alavancagem financeira. Compreendendo que o ROE é uma composição destes 3 pontos à disposição da administração da empresa, por meio do qual os investidores podem ter uma visão mais concreta a respeito do tipo de rentabilidade que se espera e da capacidade da empresa de administrá-la, observado por meio da fórmula:

Em que,

$$
R O E=\frac{L L}{\mathrm{PL}_{\mathrm{t}-1}}(2)
$$

ROE - Retorno sobre o Patrimônio Líquido

LL - Lucro Líquido

PLt-1-Total de Patrimônio Líquido

No tocante à identificação dos investimentos efetuados em capital humano, foram consideradas as informações disponibilizadas no Balanço Social das empresas. Segundo Tinoco (2001, p.14), "Balanço Social é um instrumento de gestão e de informação que visa evidenciar, da forma mais transparente possível, informações econômicas e sociais, do desempenho das entidades, aos mais diferenciados usuários, entre estes os funcionários". Dessa forma, demonstra a realidade social e econômica da empresa em um determinado período, utilizando informações simples para usuário interno e externo.

Kroetz (2000) relata que o Balanço Social é um instrumento de cunho gerencial contendo informações qualitativas e quantitativas sobre as relações do ambiente e a sociedade, permitindo a análise e verificação de problemas e oportunidades, bem como o auxílio aos gestores no processo de tomada de decisão e na elaboração de estratégias empresariais. Neste estudo foi considerado o modelo de Balanço Social proposto pelo IBASE, o qual se subdivide em: (1) Indicadores do Corpo Funcional; (2) Indicadores de organização e gestão; (3) Indicadores econômicos; (4) Indicadores sociais internos; e (5) Indicadores sociais externos - investimentos na comunidade (SCHEIBE; SOUTES, 2008).

Logo, como proxies de investimentos em capital humano adotou-se especificamente os Indicadores Sociais Internos os quais buscam evidenciar todos os investimentos realizados pela empresa em prol do bem-estar do funcionário e sua família (SOARES; LANZARIN; CASAGRANDE, 2010), bem como investimentos em programas de qualificação profissional. Dessa forma, pode-se afirmar que por meio desses indicadores é possível visualizar os principais investimentos realizados no capital humano da empresa. Com isso, as seguintes variáveis foram utilizadas para mensurar os investimentos em capital humano:

a) Alimentação (Alim) $\rightarrow$ Total de gastos com restaurante, vale-refeição, lanches, cestas básicas e outros relacionados ao cotidiano do empregado 
b) Saúde (Saud) $\rightarrow$ Compreende os gastos decorrentes de plano de saúde, assistência média, plano odontológico, programas de qualidade de vida, demais gastos com os aposentados.

c) Segurança (Segur) $\rightarrow$ Montante de gastos com programas de medicina preventiva e programas de qualidade de vida.

d) Previdência privada (Prev) $\rightarrow$ Informam-se os gastos dos planos especiais de aposentadoria, as fundações previdenciárias, as complementações de benefícios aos aposentados e dependentes.

e) Capacitação e desenvolvimento profissional (Capac) $\rightarrow$ Total de gastos com treinamentos, cursos, estágios e gastos especificamente relacionados às atividades desenvolvidas pelos funcionários.

f) Participação no resultado (Part) $\rightarrow$ Total pago aos colaboradores referentes às participações que não caracterizam remuneração salarial.

g) Educação (Educ) $\rightarrow$ Total de gastos com ensino regular em todos os níveis, incluindo valores pagos integral ou parcialmente em pós-graduação e mestrado, bem como reembolso de educação, bolsas, assinaturas em revistas e com biblioteca.

h) Creches ou Auxílio Creche (Crec) $\rightarrow$ Total de auxílio creche aos seus colaboradores.

i) Cultura (Cult) $\rightarrow$ Total de gastos relacionados a manifestações artísticas e culturais, como por exemplo, cinema, teatro, música, literatura e outras artes.

j) Outros Benefícios (Out) $\rightarrow$ Total de gastos pontais não relacionado nos itens acima como seguros pagos pela empresa, atividades recreativas, transporte, moradia, entre outros.

Com o objetivo de minimizar a discrepância do porte das empresas, as variáveis de investimento social interno foram divididas pelo total de ativos da empresa em cada ano.

Com o propósito de responder a questão da pesquisa, para o presente estudo foi utilizado o modelo de dados em painel. Conforme Baltagi (2008), os dados em painel permitem aos pesquisadores obter estimativas confiáveis e de encontrar e estimar efeitos que series temporais e cross-sections não são capazes de detectar. Esse estudo conduziu os seguintes testes, com o auxilio do software Gretl 1.9.9: dados em painel de efeitos fixos, dados em painel de efeitos aleatórios e mínimos quadrados ordinários (MQO).

$\mathrm{Na}$ equação 3, descreve-se o modelo adotado na pesquisa, o qual considera os indicadores de rentabilidade do ativo e do patrimônio líquido como proxies para a variável dependente de desempenho, e os indicadores sociais internos do Balanço Social como variáveis independentes representando os investimentos em capital humano, na forma do modelo de efeitos fixos.

$$
\begin{aligned}
\text { Desempenho } & =\beta_{0}+\beta_{1} \text { Alim }+\beta_{2} \text { Saud }+\beta_{3} \text { Prev }+\beta_{4} \text { Segur }+\beta_{5} \text { Capac }+\beta_{6} \text { Part } \\
& +\beta_{7} \text { Educ }+\beta_{8} \text { Crec }+\beta_{9} \text { Cult }+\beta_{10} \text { Out }+\varepsilon_{\text {it }}
\end{aligned}
$$

Em que,

Desempenho - Retorno sobre o Ativo ou sobre o Patrimônio Líquido

Alim - Investimentos em alimentação

Saud - Investimentos em saúde

Prev - Investimentos em previdência privada

Segur - Investimentos com programas de medicina preventiva.

Capac - Investimentos em capacitação e desenvolvimento profissional

Part - Investimentos com participação nos resultados

Educ - Investimentos em educação

R. Cont. Ufba, Salvador-Ba, v. 8, n. 3, p. 38 - 51, set-dez 2014 
Crec - Investimentos com creche e auxílio creche

Cult - Investimentos em cultura

Out - Investimentos por meio de outros benefícios

$\beta$ - Parâmetro regressor

$\varepsilon-$ Erro residual

De acordo com o objetivo destacado para a presente pesquisa e após o delineamento e o detalhamento dos procedimentos metodológicos necessários para a condução e realização do estudo, realizou-se a análise dos dados coletados de forma a verificar a relação entre os indicadores nas empresas objetos de estudo.

\section{ANÁLISE DOS DADOS}

Nesta seção apresentam-se as informações referentes aos indicadores sociais internos coletados por meio do Balanço Social das empresas analisadas e dos indicadores de rentabilidade do ativo e do patrimônio líquido representando o desempenho organizacional. Inicialmente demonstram-se a inexistência de correlações entre as variáveis explicativas do estudo e, em seguida, demonstra-se a aplicação do modelo de dados em painel para averiguar as relações entre as variáveis no intervalo de tempo apurado.

Nesse sentido, um dos pressupostos iniciais e relevantes para a análise de uma regressão é a ausência de multicolinearidade e, para constatar sua existência, apresenta-se na Tabela 1, uma matriz de correlação das variáveis explicativas elencadas no modelo estatístico apresentado.

Tabela 1 - Matriz de Correlações das Variáveis

\begin{tabular}{|c|c|c|c|c|c|c|c|c|c|c|c|c|c|}
\hline & & Alim & Prev & Saud & Segur & Educ & Cult & $\begin{array}{c}\text { Capa } \\
\text { c }\end{array}$ & Crec & Part & Out & ROA & $\begin{array}{l}\mathbf{R} \\
\mathbf{O} \\
\mathbf{E}\end{array}$ \\
\hline Alim & $\begin{array}{c}\text { Pearso } \\
\mathrm{n} \\
\text { Spearm } \\
\text { an }\end{array}$ & 1 & & & & & & & & & & & \\
\hline Prev & $\begin{array}{c}\text { Pearso } \\
\text { n } \\
\text { Spearm } \\
\text { an }\end{array}$ & $\begin{array}{c}0,029 \\
0,220^{*}\end{array}$ & 1 & & & & & & & & & & \\
\hline Saud & $\begin{array}{c}\text { Pearso } \\
\mathrm{n} \\
\text { Spearm } \\
\text { an }\end{array}$ & $\begin{array}{l}0,325^{* *} \\
0,461^{* *}\end{array}$ & $\begin{array}{c}0,039 \\
0,395^{* *}\end{array}$ & 1 & & & & & & & & & \\
\hline Segur & $\begin{array}{c}\text { Pearso } \\
n \\
\text { Spearm } \\
\text { an }\end{array}$ & $\begin{array}{c}0,114 \\
0,384 * *\end{array}$ & $\begin{array}{c}-0,014 \\
0,287^{* *}\end{array}$ & $\begin{array}{l}-0,006 \\
0,167\end{array}$ & 1 & & & & & & & & \\
\hline Educ & $\begin{array}{c}\text { Pearso } \\
\mathrm{n} \\
\text { Spearm } \\
\text { an }\end{array}$ & $\begin{array}{l}0,294 * * \\
0,318^{* *}\end{array}$ & $\begin{array}{l}0,061 \\
0,182\end{array}$ & $\begin{array}{l}0,257^{* *} \\
0,264^{* *}\end{array}$ & $\begin{array}{l}-0,096 \\
0,093\end{array}$ & 1 & & & & & & & \\
\hline Cult & $\begin{array}{c}\text { Pearso } \\
\mathrm{n} \\
\text { Spearm } \\
\text { an }\end{array}$ & $\begin{array}{c}0,031 \\
0,263^{* *}\end{array}$ & $\begin{array}{c}-0,072 \\
0,075\end{array}$ & $\begin{array}{c}0,334 \\
0,608^{* *}\end{array}$ & $\begin{array}{l}-0,132 \\
0,057\end{array}$ & $\begin{array}{c}0,04 \\
0,197^{*}\end{array}$ & 1 & & & & & & \\
\hline Capac & $\begin{array}{c}\text { Pearso } \\
\mathrm{n} \\
\text { Spearm } \\
\text { an }\end{array}$ & $\begin{array}{l}-0,025 \\
0,218^{*}\end{array}$ & $\begin{array}{c}-0,096 \\
0,154\end{array}$ & $\begin{array}{l}0,614^{* *} \\
0,568^{* *}\end{array}$ & $\begin{array}{l}0,104 \\
0,147\end{array}$ & $\begin{array}{l}-0,064 \\
0,053\end{array}$ & $\begin{array}{l}0,299^{* *} \\
0,498^{* *}\end{array}$ & 1 & & & & & \\
\hline Crec & $\begin{array}{c}\text { Pearso } \\
n\end{array}$ & $0,198 *$ & 0,069 & 0,05 & $-0,11$ & $-0,026$ & 0,022 & 0,168 & 1 & & & & \\
\hline
\end{tabular}




\begin{tabular}{|c|c|c|c|c|c|c|c|c|c|c|c|c|}
\hline & $\left|\begin{array}{c}\text { Spearm } \\
\text { an }\end{array}\right|$ & $0,450^{* *}$ & $0,398 * *$ & $0,426^{* *}$ & 0,058 & 0,078 & $0,204^{*}$ & $0,296^{* *}$ & & & & \\
\hline \multirow[b]{2}{*}{ Part } & $\begin{array}{c}\text { Pearso } \\
\mathrm{n}\end{array}$ & 0,157 & $-0,024$ & $0,350 * *$ & 0,037 & $-0,004$ & $-0,082$ & $0,516^{* *}$ & 0,112 & \multirow[b]{2}{*}{1} & & \\
\hline & $\begin{array}{c}\text { II } \\
\text { an }\end{array}$ & $0,328^{* *}$ & 0,168 & $0,502^{* *}$ & $0,283^{* *}$ & 0,129 & 0,148 & $0,431^{* *}$ & $0,321 * *$ & & & \\
\hline \multirow{2}{*}{ Out } & $\begin{array}{c}\text { Pearso } \\
\mathrm{n}\end{array}$ & 0,126 & 0,154 & $0,211^{*}$ & 0,095 & 0,054 & 0,018 & 0,163 & 0,01 & $0,317^{* *}$ & \multirow{2}{*}{1} & \\
\hline & $\begin{array}{c}\text { Spearm } \\
\text { an }\end{array}$ & 0,177 & $0,273^{* *}$ & $0,417^{* *}$ & 0,16 & 0,14 & 0,193 & $0,246^{* *}$ & $0,260^{* *}$ & $0,394 * *$ & & \\
\hline \multirow{2}{*}{ ROA } & $\begin{array}{c}\text { Pearso } \\
\mathrm{n}\end{array}$ & $\stackrel{-}{-}$ & $-0,132$ & $\stackrel{-}{-}$ & $-0,152$ & $-0,098$ & $-0,198$ & $-0,17$ & $-0,023$ & $-0,126$ & $\overline{-}^{-}, 430^{* *}$ & \multirow{2}{*}{1} \\
\hline & $\begin{array}{c}\text { Spearm } \\
\text { an }\end{array}$ & $0,274 * *$ & 0,05 & $\stackrel{-}{0,346^{* *}}$ & $-0,16$ & $-0,051$ & $-0,306^{* *}$ & $-0,039$ & 0,023 & $-0,04$ & $\overline{-}^{-}$ & \\
\hline \multirow{2}{*}{ ROE } & $\begin{array}{c}\text { Pearso } \\
\mathrm{n}\end{array}$ & $0, \overline{-}$ & $-0,052$ & $-0,248^{*}$ & $-0,109$ & 0,042 & $-0,165$ & $-0,067$ & $-0,026$ & 0,061 & $0,275^{\text {*** }}$ & \multirow[b]{2}{*}{$0,769^{* *}$} \\
\hline & $\begin{array}{c}\text { Spearm } \\
\text { an }\end{array}$ & ${ }^{-}, 384 * *$ & $-0,036$ & $-0,250^{*}$ & $-0,183$ & $-0,096$ & $-0,370 * *$ & 0,026 & 0,146 & $0,205^{*}$ & $-0,259^{*}$ & \\
\hline
\end{tabular}

*significância a 0,1; **significância a 0,05; ***significância a 0,01

Fonte: Dados da Pesquisa.

Para maior robustez da análise, utilizou-se como parâmetros os coeficientes de relação de Pearson e Spearman. Observou-se na análise da matriz, uma baixa correlação entre as variáveis explicativas. Esse resultado a priori fornece indícios de baixa multicolinearidade. Contatou-se a presença de correlação significativa entre os indicadores de desempenho e algumas variáveis de investimento social, com destaque para o investimento em alimentação que apresentou uma relação negativa em ambos os coeficientes, indicando que investimentos na alimentação dos funcionários podem estar relacionados ao desempenho das empresas da amostra.

Com o propósito de analisar a relação do desempenho dos indicadores sociais internos e o desempenho organizacional, realizou-se um estudo de dados em painel. Inicialmente, adotou-se o modelo pooled (Mínimos Quadrados Ordinários - MQO), utilizando os indicadores sociais internos como variáveis explicativas e os indicadores de retorno sobre ativo e sobre o patrimônio líquido como proxies do desempenho das empresas. A partir dos resultados, foram realizados os testes de diagnóstico de painel, com o objetivo de identificar o modelo mais adequado para a regressão.

O primeiro teste realizado foi o estimador de efeitos fixos e partindo da hipótese de que o modelo pooled é o mais apropriado, a rejeição de $\mathrm{H}_{0}$ indica que o modelo de efeitos fixos é mais conveniente. Por seguinte, a utilização do teste de Breusch-Pagan visa decidir qual dos modelos é mais apropriado, ou seja, o modelo pooled ou o modelo de efeitos aleatórios. A hipótese nula $\left(\mathrm{H}_{0}\right)$ do teste adota o modelo pooled que deve ser usado. Por fim, o teste de Hausman, consiste em decidir entre o modelo de efeitos aleatórios e efeitos fixos qual é o mais consistente e eficiente. Sua $\mathrm{H}_{0}$ assume que o modelo de efeitos aleatórios é melhor.

Tabela 2 - Testes de dados em painel

\begin{tabular}{lc}
\hline \hline Testes & p-value \\
\hline Estimador de Efeitos Fixos & 0,0000 \\
Breusch-Pagan & 0,0000 \\
Hausman & 0,0249 \\
\hline \hline
\end{tabular}

Fonte: Dados da Pesquisa.

Na Tabela 2, estão dispostos os resultados dos testes dos dados em painel e seus respectivos níveis de significância. Decorrente a isso, assumiu-se a utilização do modelo de efeitos fixos como o mais consistente.

Tabela 3 - Modelo de Efeitos-fixos (ROA)

R. Cont. Ufba, Salvador-Ba, v. 8, n. 3, p. 38 - 51, set-dez 2014 


\begin{tabular}{lcccccc}
\hline \hline & Coeficiente & Erro Padrão & razão-t & p-valor & \\
\cline { 5 - 6 } \cline { 5 - 6 } Const. & 9,3657 & 2,97084 & 3,1525 & 0,00245 & $* * *$ \\
Alimentação & $-741,264$ & 994,849 & $-0,7451$ & 0,45890 & \\
Previdência & $-120,005$ & 89,2857 & $-1,3441$ & 0,18360 & \\
Saúde & 1367,8 & 777,728 & 1,7587 & 0,08333 & $*$ \\
Segurança & $-3146,71$ & 1271,02 & $-2,4757$ & 0,01591 & $* *$ \\
Educação & 4783,2 & 8238,02 & 0,5806 & 0,56350 & \\
Cultura & 2613,97 & 18382,7 & 0,1422 & 0,88736 & \\
Capacitação & $-1643,14$ & 2293,25 & $-0,7165$ & 0,47624 & \\
Creches & 6335,77 & 14206,6 & 0,4460 & 0,65710 & \\
Participação & 1402,85 & 494,325 & 2,8379 & 0,00605 & $* * *$ \\
Outros & $-1975,36$ & 832,423 & $-2,3730$ & 0,02061 & $* *$ \\
\hline R-quadrado ajustado & & & & 0,718129 & \\
P-valor(F) & & & & 0,000000 & \\
\hline \hline
\end{tabular}

*significância $<0,10 ; * *$ significância $<0,05 ; * * *$ significância $<0,01$.

Fonte: Dados da Pesquisa.

$\mathrm{Na}$ Tabela 3, observa-se que as variáveis sociais internas explicam aproximadamente $72 \%$ do Retorno sobre o Ativo. Este resultado vai ao encontro dos achados da pesquisa de Da Silva et al. (2013), os quais verificaram uma relação positiva entre investimentos em capital humano e o ROA, destacando que as empresas que investiram mais em capital humano foram aquelas que obtiveram melhor desempenho econômico-financeiro.

Entretanto, notou-se que apenas quatro indicadores apresentam relação significativa com a variável de desempenho. O modelo descreve que em média as empresas aumentam seu retorno sobre o ativo quando investem em programas de saúde e participações nos resultados. Contudo investimentos em segurança e outros benefícios, como atividades recreativas, refletem negativamente no desempenho. Nesse sentido, Graça (2011) destaca que investimentos em capital humano podem afetar tanto positiva quando negativamente o desempenho das empresas.

Tabela 4 - Modelo de Efeitos-fixos (ROE)

\begin{tabular}{|c|c|c|c|c|c|}
\hline & Coeficiente & Erro Padrão & razão-t & p-valor & \\
\hline Const. & 23,3635 & 5,40211 & 4,3249 & 0,00005 & $* * *$ \\
\hline Alimentação & $-2128,72$ & 1809,01 & $-1,1767$ & 0,24359 & \\
\hline Previdência & $-410,078$ & 162,355 & $-2,5258$ & 0,01399 & $* *$ \\
\hline Saúde & 2404,51 & 1414,2 & 1,7003 & 0,09386 & $*$ \\
\hline Segurança & $-10801,7$ & 2311,2 & $-4,6736$ & 0,00002 & $* * *$ \\
\hline Educação & 41668,2 & 14979,8 & 2,7816 & 0,00707 & $* * *$ \\
\hline Cultura & $-9619,22$ & 33426,7 & $-0,2878$ & 0,77444 & \\
\hline Capacitação & $-3684,02$ & 4169,99 & $-0,8835$ & 0,38024 & \\
\hline Creches & $-593,141$ & 25833 & $-0,0230$ & 0,98175 & \\
\hline Participação & 2979,75 & 898,87 & 3,3150 & 0,00150 & $* * *$ \\
\hline Outros & $-3379,46$ & 1513,66 & $-2,2326$ & 0,02902 & $* *$ \\
\hline R-quadrado ajustado & & & & 904743 & \\
\hline P-valor(F) & & & & 000000 & \\
\hline
\end{tabular}

*significância < 0,10; **significância <0,05; ***significância <0,01.

Fonte: Dados da Pesquisa.

De acordo com a Tabela 4, o modelo demonstra uma relação significativa entre as variáveis sociais internas e o retorno sobre o patrimônio líquido. Contatou-se que investimentos no ISI

R. Cont. Ufba, Salvador-Ba, v. 8, n. 3, p. 38 - 51, set-dez 2014 
podem explicar até aproximadamente $90 \%$ do retorno dos acionistas. Os resultados elencados assemelham-se aos encontrados por Katou (2008), o qual destaca que os investimentos em capital humano das entidades apresentam relações com o desempenho organizacional.

É interessante observar que conforme o modelo, o ROE é influenciado positivamente por investimentos em programas de saúde, participação no resultado e educação. Em contrapartida, investimentos relacionados a previdências privadas, segurança e outros benefícios minimizam o desempenho organizacional. Apesar dos investimentos em alimentação apresentarem uma relação negativa com o desempenho, como observado por meio da análise de correlação, os mesmos não apresentam significância estatística.

Dessa forma, os achados da presente pesquisa estão em linha com os resultados evidenciados na literatura, como os de Katou (2008) e Graça (2011), os quais verificaram que investimentos efetuados em capital humano podem impactar positiva e negativamente o desempenho das organizações.

\section{CONCLUSÕES}

As entidades que atuam com o propósito lucrativo buscam melhorar continuamente seu desempenho econômico-financeiro. Em virtude disso, alocam recursos econômicos escassos como o capital, recursos físicos, tecnologia e recursos humanos no intuito de, se bem geridos, produzir bens e serviços que cumpram as infinitas necessidades de seus clientes (TINOCO, 2001).

O objetivo deste trabalho consistiu em estudar a relação entre os indicadores sociais internos e o desempenho em companhias abertas que divulgam o Balanço Social, a partir dos dados coletados das Demonstrações publicadas nos sites das empresas analisadas e dos indicadores de Rentabilidade, a partir da listagem das empresas que publicaram Balanço Social nos anos de 2006 e 2010.

Os testes estatísticos demonstram haver baixa multicolinearidade das variáveis exploratórias. Constatou-se, também, a presença de uma correlação negativa significativa entre a variável de alimentação e desempenho. Entretanto, essa relação não obteve significância nos modelos de dados em painel.

Para a análise de dados em painel, foram utilizados os indicadores sociais internos, tal como propostos pelo modelo IBASE, como variáveis explicativas. Como proxies do desempenho organizacional foram empregados os indicadores de rentabilidade: ROA (retorno sobre Ativo) e ROE (Retorno sobre Patrimônio Líquido). Percebe-se no decorrer do trabalho que os investimentos em capital humano tornam-se relevantes para o crescimento e o sucesso das empresas, considerando que, para resistir à pressão dos concorrentes e à competitividade do mercado, fazem-se necessários constantes melhorias e adaptações no corpo funcional (GRAÇA, 2011).

Com a utilização do modelo de dados em painéis com efeito fixo, constatou relação significativa em algumas variáveis com o retorno do ativo. Dentre elas, cabe destacar a relação positiva dos investimentos em programas de saúde e participação nos resultados, os quais demonstraram significância a $10 \%$ e 1\%, respectivamente. Em contrapartida, investimentos em segurança e outros benefícios, como atividades recreativas, apresentaram uma relação negativa a $5 \%$ de significância.

O Retorno sobre Patrimônio Líquido pode ser explicado pelas variáveis sociais internas em até $90 \%$. O modelo demonstra que investimentos em programas de participação em resultados e programas educacionais tem uma relação positiva e significante a $1 \%$ com o retorno sobre 
investimento de acionistas. Entretanto, além dos investimentos em segurança, os investimentos em previdência privada também assumem uma relação negativa com o ROE.

Por fim, os resultados demonstram que investimentos em capital humano na organização apresentam resultados conflitantes. Visto que, quando os investimentos estão alinhados com programas de saúde, educação e participação nos resultados o desempenho da empresa tende a responder positivamente. Contudo, quando a empresa aplicar parte de seu capital em programas de segurança e previdência privada o desempenho tende a ser minimizado.

A limitação principal deste estudo consiste no número de empresas que divulgam em seus sites as Demonstrações do Balanço Social e com isso inúmeras entidades não puderam fazer parte da amostra por não corresponderem aos requisitos principais para formação da amostra. Limitase também quanto ao período analisado, ponderando-se que a investigação de um período de tempo maior poderá aprofundar o entendimento sobre o tema e gerar novar interpretações aos dados. Logo, pela complexidade e grande quantidade dos dados estudados, acredita-se que uma amostra maior de dados pode oferecer resultados mais conclusivos.

A partir deste fato, como contribuição para trabalhos futuros, sugere-se a utilização de uma amostra maior de dados, a fim de tentar proporcionar mais indícios da relação entre os investimentos no corpo funcional e o desempenho das entidades. Sugere-se também o uso de outras métricas para mensurar o desempenho das empresas, com o objetivo de revelar novos resultados e possivelmente ampliar a explicação do modelo traçado.

\section{REFERÊNCIAS}

ANTUNES, Maria. T. P. Capital Intelectual. São Paulo: Atlas, 2000.

ANTUNES, Maria. T. P.; MARTINS, Eliseu. Gerenciando o capital intelectual: uma abordagem empírica baseada na controladoria de grandes empresas brasileiras. Revista Eletrônica de Administração, v.13, n.1, p. 1-22, 2007.

ARTUR, Jeffrey B. Effects of Human Resource Systems on Manufacturing Performance and Turnover. Academy of Management Journal. v. 37, p. 670-687, 1994.

ASSAF NETO, Alexandre. Finanças corporativas e valor. São Paulo: Atlas, 2003.

BAPTISTE, Ian. Education Lone Wolwes: Pedagogical Implicacions Of Human Capital Theory. Adult Education Quartely. v. 51, p. 184-201, 2001.

BECKER, Gary. S. Investment in Capital Human: a theoretical analysis. The Journal of Political Economy. v. 70, p.9-49, 1962.

COLAUTO, Romualdo D.; BEUREN, Ilse M. Proposta Para Avaliação Da Gestão Do Conhecimento Em Entidades Filantrópicas: O Caso De Uma Organização Hospitalar. Revista Administração Contemporânea. v. 7, n. 4, 2003.

CRAWFORD, Richard. Na era do capital humano: o talento a inteligência e o conhecimento como forças econômicas, seu impacto nas empresas e nas decisões de investimento. Trad. Luciana B. Gouveia. São Paulo: Atlas, 1994.

CUNHA, Jacqueline. V. A. Doutores em Ciências Contábeis da FEA/USP: Análise sob a ótica da teoria do Capital Humano. Tese de Doutorado em Controladoria e Contabilidade, 
Departamento de Contabilidade e Atuária da Faculdade de Economia, Administração e Contabilidade da Universidade de São Paulo, 2007.

SILVA, Jonas Ismael da et al. Capital humano e o desempenho econômico-financeiro de empresas brasileiras do setor elétrico. ASAA-Advances in Scientific and Applied Accounting, v. 6, n. 1, p. 31-48, 2013.

GRAÇA, Maria. I. B. R. G. O investimento em capital humano e a criação de valor para a empresa: uma aplicação às unidades hospitalares E.P.E. Portuguesas. Dissertação de Mestrado em Contabilidade e Finanças - Instituto Superior de Contabilidade e Administração do Porto, 2011.

KATOU, Anastasia A. Measuring the impact of HRM on organizational performance. Journal of Industrial Engineering and Management. v. 1, p. 119-142, 2008.

KAPLAN Robert.; NORTON, David. The Balanced Scorecard: Translating Strategy into action. Harvard, Business School Press. Boston, 1996.

KROETZ, César E. S.. Balanço social, teoria e prática. São Paulo: Atlas, 2000.

MIZUMOTO, Fábio. M.; ARTES, Rinaldo; LAZZARINI, Sérgio. G.; HASHIMOTO, Marcos; BEDÊ, Marco A. A sobrevivência de empresas nascentes no estado de São Paulo: um estudo sobre capital humano, capital social e práticas gerenciais. Revista de Administração. v.45, p. 343-355, 2010.

RASULA, Jelena.; VUKSIC, Vesna. B.; STEMBERGER, Mojca. I. The impact of knowledge management on organisational performance. Economicand Business Review. v. 14, n. 2, p. 147-168, 2012.

SCHEIBE, Margarete. L; SOUTES, Dione O. Responsabilidade Social: um estudo de caso em uma cooperativa paranaense. Congresso USP de Controladoria e Contabilidade, 5, 2008. São Paulo. Anais ... São Paulo, USP, 2008.

SCHULTZ, Theodore W. Investment in Human Capital. The American Economic Review. v. 51 , p. $1-17,1961$.

SNELL, Scott; DEAN, James. Integrated Manufacturing and human resource management: a human capital perspective. Academy of Management Journal, v. 35, n. 3, p. 476-504, 1992.

SOARES, Sandro V.; LANZARIN, Jovani; CASAGRANDE, Maria D. H.. Análise estatística do modelo IBASE de balanço social de uma empresa do setor de siderurgia. Revista Enfoque Reflexão Contábil. Maringá, Universidade Estadual de Maringá, v. 29, n. 2, p. 27-39, maiago 2010.

STEWART, Thomas. A. Capital intelectual: a nova vantagem competitiva das empresas. Rio de Janeiro: Campus, 1998.

SVEIBY, Karl. E. A Nova riqueza das organizações. Rio de Janeiro: Campus, 1998. 
TEECE, David J. Strategies for Managing Knowledge Assets: the Role of firm Structure and Industrial Context. Long Range Planning.v. 33, p. 35-54, 2000.

TINOCO, João E. P. Balanço social: uma abordagem da transparência e da responsabilidade pública das organizações. São Paulo: Atlas, 2001.

YANG, Jie. The knowledge management strategy and its effect on firm performance: a contigency analysis. International Journal Production Economics.v. 125, p. 215-223, 2010 . 